\title{
Retraction Note to: Forest rainfall characteristics based on heterogeneous computing and influencing factors of athletes' physical supplement
}

\author{
Yujia Liu ${ }^{1} \cdot$ Min Chen ${ }^{1} \cdot$ Xiaoqin Xu ${ }^{1}$
}

Published online: 9 November 2021

C Saudi Society for Geosciences 2021

Retraction Note to: Arabian Journal of Geosciences (2021) 14: 1516 https://doi.org/10.1007/s12517-021-08025-y

The Editor-in-Chief and the Publisher have retracted this article because the content of this article is nonsensical. The peer review process was not carried out in accordance with the Publisher's peer review policy. Author Yujia Liu has not responded to correspondence regarding this retraction. The Publisher has not been able to obtain a current email address for authors Min Chen and Xiaoqin Xu.

Publisher's note Springer Nature remains neutral with regard to jurisdictional claims in published maps and institutional affiliations.

The original article can be found online at https://doi.org/10.1007/ s12517-021-08025-y.

Yujia Liu

liuyujia10030512@163.com

1 School of Physical Education, Hunan International Economics University, Changsha, Hunan Province, China 